Published in final edited form as:

Gastroenterology. 2019 May ; 156(7): 1969-1978. doi:10.1053/j.gastro.2018.12.043.

\title{
Pancreatitis in Children
}

\author{
Aliye Uc ${ }^{1}$, Sohail Z. Husain ${ }^{2}$ \\ ${ }^{1}$ University of lowa, Stead Family Children's Hospital, lowa City, lowa \\ ${ }^{2}$ Children's Hospital of Pittsburgh, Pittsburgh, Pennsylvania
}

\begin{abstract}
Acute, acute recurrent, and chronic forms of pancreatitis have been increasingly diagnosed in children in the past 2 decades. Risk factors in the pediatric group are broad and appear to be strikingly different compared with the adult cohort. However, the disease burden and impact on quality of life are surprisingly similar in children and adults. This review summarizes the definitions, epidemiology, risk factors, diagnosis, and management of pediatric pancreatitis, identifies features that are unique to the childhood-onset disease, identifies gaps, and proposes recommendations for future opportunities.
\end{abstract}

\section{Keywords}

Children; Genetic; Exocrine Pancreatic Insufficiency; Diabetes

\section{Definitions, Diagnostic Criteria, and Epidemiology}

It was once believed that pediatric acute pancreatitis (AP) and chronic pancreatitis (CP) were very uncommon. However, over the past 2 decades, reports from several regional centers have shown that the incidence of childhood AP is in the range of 3-13 cases per 100,000 persons per year, ${ }^{1-5}$ which overlaps with the lower end of the range in adults (5-60 cases per 100,000 persons per year). ${ }^{6-8}$ Pancreatitis is a clinical diagnosis based on a combination of history, physical examination, laboratory testing, and imaging findings as listed in Table $1 .{ }^{9}$

Physicians from centers that perform total pancreatectomy and islet autotransplantation (TPIAT) report a sizable number of children with $\mathrm{CP},{ }^{10}$ confirming that the incidence and prevalence of pediatric $\mathrm{CP}$ should be substantial. However, 2 population studies that included children in their cohort found an incidence of CP in children of w0.5 per 100,000 persons per year, ${ }^{11,12}$ which was only approximately one eighth the incidence reported in adults. Recent work by Sellers et $\mathrm{al}^{5}$ used a large US private health insurance database that, unlike most previous studies, captured inpatient admissions and outpatient encounters. The study confirmed the incidence of AP in children as 12 cases per 100,000 persons per year.

Reprint requests Address requests for reprints to: Aliye Uc, MD, Stead Family Department of Pediatrics, The University of Iowa Carver College of Medicine, BT1120-C, 200 Hawkins Drive, Iowa City, Iowa 52242. aliye-uc@uiowa.edu.

Conflicts of interest

The authors disclose the following: Aliye Uc is a member of American Board of Pediatrics and sub-board of Pediatric

Gastroenterology. Sohail Z. Husain owns equity in PrevCon. 
The incidence of pediatric CP was higher than in previous reports, at 2 cases per 100,000 persons per year, and the prevalence was 6 cases per 100,000 persons. Although there are fewer children with pancreatitis compared with adults, the burden of disease in children is currently recognized as more impactful than previously appreciated. ${ }^{13-15}$

As with the adult literature, there have been reports of large increases in the number of children admitted to the hospital with pancreatitis. ${ }^{1,3,4,16}$ Sellers et al $^{5}$ reported that the incidence of pediatric AP had stabilized from 2007 to 2014 and that the incidence of pediatric $\mathrm{CP}$ had even slightly decreased. The former finding was corroborated by Hornung et al. ${ }^{17}$ The reasons for the initial increase are likely due to a combination of factors, including greater awareness about pancreatitis in children ${ }^{1}$ and therefore a higher likelihood of testing for pancreatitis, clear definitions of $\mathrm{AP}$ and $\mathrm{CP}^{18,19}$ (Table 1), increased referral patterns to tertiary care centers where most of these reports are derived, ${ }^{3}$ and an overall increasing incidence of biliary pancreatitis because of higher obesity rates. ${ }^{20}$

\section{Risk Factors}

In more than a fifth of cases in children, pancreatitis results from more than 1 contributing factor $^{3}$; therefore, it is more appropriate to attribute risk factors to the development of pancreatitis rather than to list a single etiology. In children, the risk factors are more proportionately varied than in adults, as shown in Figure 1. ${ }^{14,21}$ Several of these risk factors offer unique opportunities to study pancreatic physiology and pathophysiology.

\section{Genetic Associations}

Genetic causes account for fewer than $10 \%$ of all comers with pediatric $\mathrm{AP}^{4}$ but for more than $50 \%$ of cases with acute recurrent pancreatitis (ARP) and w75\% of cases with CP. ${ }^{1}$ The mutations that are most commonly associated with pediatric pancreatitis are in the cationic trypsinogen $(P R S S 1)$, cystic fibrosis transmembrane generator, serine protease inhibitor Kazal type I (SPINK1), and chymotrypsin C genes. This is a striking difference between the pediatric and adult cohorts. Several pediatric studies report genetic variants associated with $\mathrm{CP},{ }^{14,22-26}$ whereas adult studies describe environmental risk factors, particularly alcohol and smoking. ${ }^{12,27-29}$ Longitudinal and prospective studies that involve pediatric and adult cohorts are needed to determine whether this is related to penetrance of certain mutations in the pediatric group and/or the synergy between genetic and environmental factors.

Recent studies also demonstrate that genetic risk factors can determine disease behavior. PRSS1, SPINK1, and chymotrypsin C gene c.180TT variants can present at any age with pancreatic disease and are more commonly associated with pediatric CP compared with $\mathrm{ARP}^{13,14,30}$; PRSS1, chymotrypsin C gene, and carboxypeptidase 1 gene mutations predispose children to early-onset CP. ${ }^{1,31}$ Carboxyl ester lipase and carboxyl ester lipase hybrid gene ${ }^{32,33}$ variants increase the risk for $\mathrm{CP}$ in adults. Early identification of genetic risk factors could enable precision medicine approaches in ARP and CP.

The pediatric cohort is unique with almost negligible environmental factors (ie, alcohol and smoking) and high prevalence of gene mutations in ARP and CP. Future studies are 
underway to identify genetic markers that predict rapid progression from AP to ARP and CP and the development of chronic pain, exocrine pancreatic insufficiency, and diabetes.

\section{Anomalies of the Pancreas}

Five percent to $20 \%$ of children with AP have pancreas anomalies that are associated with pancreatitis. ${ }^{34,35}$ The most common anomaly is pancreas divisum, a situation in which the main pancreatic duct (PD) drains into the minor papilla through the duct of Santorini, whereas it drains separately into the major papilla through the duct of Wirsung. ${ }^{36}$ Although approximately $7 \%$ of the general population has pancreas divisum and the overwhelming majority never develops pancreatitis, there are several reports demonstrating that children with ARP and CP have a higher frequency of pancreas divisum than the general population. ${ }^{37}$ Many of these patients with pancreas divisum have additional risk factors. ${ }^{38,39}$ The finding suggests that there might be a small subset of patients with divisum who develop obstructive pancreatitis or that the anomaly overall confers an additive risk (on top of other risk factors) for developing pancreatitis. Children with PD undergo multiple endoscopic procedures, pancreatic sphincterotomy, or minor papillotomy, but endoscopic retrograde cholangiopancreatography (ERCP) has been found helpful only when pancreatic ductal stones are present. ${ }^{37}$ Similar to the newly launched Sphincterotomy for Acute Recurrent Pancreatitis trial in adults, ${ }^{40}$ it will be important to examine in a randomized fashion whether children with ARP and pancreas divisum truly benefit from the intervention of minor sphincterotomy. Other pancreas anomalies associated with pancreatitis are pancreaticobiliary malunion, choledochal cyst, and annular pancreas. ${ }^{41}$ Intestinal duplication also has been reported as a trigger for pancreatitis. ${ }^{42}$ In all these anomalies, the mechanism of pancreatitis is likely due to outlet obstruction resulting in ductal hypertension.

\section{Gallstones and Microlithiasis}

As in adults, obstruction with gallstones or microlithiasis (also known as sludge) at the outlet of the common bile duct and PD will cause ductal hypertension ${ }^{43}$ and induce AP. ${ }^{44}$ Biliary pancreatitis is currently the most common cause of AP in children, ranging from $3 \%$ to $30 \%$ of all cases. ${ }^{4}$ With notable exceptions, only few cases of pediatric ARP or CP can be attributed to biliary pancreatitis, because the diagnosis is usually made early in the course, followed by cholecystectomy that should be curative. Because the diagnosis of microlithiasis is often elusive, children will often undergo cholecystectomy for even soft signs of microlithiasis, such as the occasional presence of sludge in the common bile duct, even in the absence of common bile duct dilatation. Further, patients with idiopathic ARP are often advised to have the surgery as an empiric measure for presumed microlithiasis. Although there is some controversy ${ }^{45}$ there are prominent reports of decreased frequency of pancreatitis bouts after the surgery. ${ }^{46,47}$ Areas for further investigation include better diagnostic modalities for microlithiasis in children and longitudinal evaluation of children with idiopathic pancreatitis who underwent cholecystectomy.

\section{Medications}

Unlike in adults, medications are recognized as a frequent risk factor for pancreatitis in children, contributing up to a fourth of cases, and approximately a third of medicationassociated cases of AP have additional risk factors identified. ${ }^{48}$ The common medications 
are antiepileptics, notably valproic acid; the cancer drug asparaginase; and immunomodulators such as thiopurines, mesalamine, and corticosteroids. Establishing causality for a particular drug as a risk factor for pancreatitis requires several lines of evidence, including whether there is a clear temporal sequence, a typical latency period, recurrence of pancreatitis after a repeat challenge, or known mechanisms for the development of pancreatitis with the drugs. ${ }^{49,50}$ Recently, HLA subtypes DQA1 and DRB1 were found to confer susceptibility to thiopurine pancreatitis. ${ }^{51,52}$ Based on experimental animal models, valproic acid appears to predispose to pancreatitis by dampening the ability of the pancreas to regenerate after injury. ${ }^{53}$ It has long been speculated that asparaginase triggers pancreatitis in patients who have an intrinsic inability to counteract depletion of pancreatic asparagine. ${ }^{54} \mathrm{~A}$ better understanding of the mechanisms underlying pancreatitis from these types of medications will (1) provide guidance of which patients to prescribe the medication, (2) help devise preventatives or rescue therapies, and, on a broader level, (3) will elucidate the intricate physiology of nutrient handling in the translationally active exocrine pancreas. ${ }^{55}$ To categorically design useful decision-making guidelines for medicationassociated pancreatitis, what also is required is a comprehensive analysis of patient information in the form of a database framework that resembles the existing Drug-Induced Liver Injury Network. ${ }^{56}$

\section{Additional Risk Factors}

Additional risk factors that need to be considered in the child presenting with pancreatitis include trauma, metabolic disorders, infections, systemic disease, and autoimmune pancreatitis. Blunt abdominal trauma can cause pancreatitis by disrupting the PD. ${ }^{57}$ Traumatic events in children are motor vehicle accidents, forward collision onto bicycle handlebars, other sports-related injuries, and, importantly, nonaccidental trauma from child abuse. Metabolic disorders to consider in children include diabetic ketoacidosis, hypertriglyceridemia, hypercalcemia, which in children occurs mostly from the nonmalignant condition of hyperparathyroidism, and inborn errors of metabolism. ${ }^{50}$ Among inborn errors of metabolism, branched-chain amino acidurias such as propionic acidemia and methylmalonic acidemia are notable risk factors for ARP in infants and toddlers. In these patients, there is a rough correlation of improvement in pancreatitis with control of the metabolic disturbance and as patients advance beyond toddlerhood, ${ }^{58}$ suggesting a direct impact of intracellular acidemia to the development of pancreatitis. ${ }^{59}$ Many primary infections have been associated with pancreatitis, and in some cases, the infection was isolated from pancreas samples. ${ }^{60,61}$ Infections include mumps, the herpes family of viruses, influenza, the named hepatitis viruses, and salmonella. In most cases, as with the medication associations, a diagnosis of infection-related pancreatitis is challenging and requires a thorough history of known sick contacts, a characteristic prodrome with typical signs and symptoms of the infection, or isolation of the suspected pathogen from the host. It has been known for some time that critically ill patients with sepsis or patients with acute flares of a pre-existing systemic disease will develop AP. The systemic diseases reported in children include hemolytic uremic syndrome, systemic lupus erythematosus, ${ }^{62}$ Henoch-Schönlein purpura, ${ }^{63,64}$ Kawasaki disease, ${ }^{65}$ and inflammatory bowel disease. ${ }^{66}$ The mechanisms for pancreatitis in these situations are unclear and, therefore, open to a wealth of investigation. They could turn out to be multifactorial and could include pancreatic ischemia from 
localized vasoconstriction or cytokine priming from the inflammatory storm of the systemic affliction. Autoimmune pancreatitis in children more commonly mirrors the type 2 variant similar to idiopathic duct centric pancreatitis. ${ }^{67,68}$ Unlike the type 1 variant, patients with idiopathic duct centric pancreatitis usually have normal serum immunoglobulin G4 levels, are responsive to steroids, and have (at least based on current follow-up periods) low recurrence rates. Thirty percent of these patients develop inflammatory bowel disease before or after the diagnosis of idiopathic duct centric pancreatitis.

\section{Clinical Manifestations and Diagnosis of Pancreatitis in Children}

For detailed information, please refer to the most recent evidence-based diagnosis and management guidelines. ${ }^{69}$ In general, AP is a clinical diagnosis based on a patient's history and physical examination as supported by laboratory test results and imaging findings as necessary (Table 1). Although most adolescents and adults present during a bout of AP with characteristic severe epigastric pain that can radiate to the back, young children, especially infants and toddlers, most often present with nonfocal abdominal discomfort and irritability. ${ }^{62,70}$ Particularly in infants, in whom pancreatic amylase production is physiologically low, serum lipase is a more reliable marker for making a diagnosis of pancreatitis. In 1 study, serum amylase failed to diagnose pancreatitis in one third of infants compared with the lipase. $^{70}$

AP can be classified as mild, moderately severe, or severe according to North American Society of Pediatric Gastroenterology, Hepatology and Nutrition Pancreas Committee Recommendations. ${ }^{71}$ Mild AP is defined by AP without organ failure or local or systemic complications and usually resolves in the first week. Moderately severe AP is defined by the presence of transient organ failure that resolves in less than 48 hours, local complications, or exacerbation of comorbidity. Severe AP is defined by persistent organ dysfunction for longer than 48 hours. The presence of systemic inflammatory response syndrome is associated with increased risk for persistent organ dysfunction. Several scoring systems have been described in pediatrics to predict the severity of AP. ${ }^{72,73}$

Transabdominal ultrasound remains the first choice of imaging in pediatric facilities because of its wide availability, low cost, and absence of ionizing radiation. Cross-sectional imaging is not usually necessary to diagnose pancreatitis, although it could be useful to assess for pancreatic necrosis or other fluid collections during the course of hospitalization or to search for biliary pancreatitis at admission. ${ }^{74}$ Endoscopic ultrasound (EUS) is currently available at only a few pediatric centers. With a larger cadre of advanced pediatric endoscopists on the horizon, EUS could offer a quick diagnosis of biliary pancreatitis in children with a transition to ERCP within the same procedural block of anesthesia.

Children with ARP in general are in normal health between episodes. Children with CP have pain that varies from mild to severe and from episodic to constant ${ }^{13}$; evaluation of pain can be difficult in younger children who cannot process and verbalize the pain. Pediatric CP leads to an enormous health burden with the increased number of emergency room visits, missed school days, hospitalizations, and medical, surgical, and endoscopic therapies. ${ }^{14,15}$ Because the pancreas is further damaged, children with CP develop exocrine pancreatic 
insufficiency (EPI) and diabetes. In the International Study Group of Pediatric Pancreatitis: In Search for a Cure (INSPPIRE) cohort, $34 \%$ of children had EPI and $1 \%$ had diabetes at the time of enrollment to the study. ${ }^{13}$

Guidelines for the evaluation of pediatric ARP and $\mathrm{CP}$ were recently proposed by the INSPPIRE group ${ }^{74}$ (Table 2). The diagnosis requires a careful evaluation, a medical history inquiring about possible past pancreatitis attacks, recurrent abdominal pain, hospitalizations, and emergency room visits. Family history of pancreatitis, diabetes, gallbladder disease, and pancreatic cancer should be sought.

There was a strong consensus among INSPPIRE members on the diagnostic criteria for AP, ARP, and CP (Table 1) and evaluation for certain biochemical parameters as part of the initial workup (serum aspartate aminotransferase, alanine aminotransferase, $\gamma$-glutamyl transferase, total and direct bilirubin, fasting triglycerides, calcium).$^{74}$ In certain circumstances, the panel agreed to test for parasitic diseases, metabolic disorders, and celiac disease. There was strong agreement to minimize radiation exposure in children. Genetic mutations were considered a significant risk factor, but genetic testing was encouraged only for PRSS1 mutations and to confirm cystic fibrosis by sweat chloride if suspected. If cystic fibrosis was strongly suspected and the sweat chloride result was borderline or not diagnostic, the recommendation was referral to a specialized center.

Imaging studies will confirm acute inflammatory (ie, AP or ARP) or chronic irreversible changes (ie, $\mathrm{CP}$ ) in the pancreas and could provide clues to the risk factors, mostly obstructive. Transabdominal ultrasound is the first imaging test of choice, but it might not delineate the anatomy of the pancreas in detail. Computed tomography will visualize acute and chronic changes, including pancreas atrophy, calcifications, and fat replacement, but it will not detect subtle parenchymal changes or ductal abnormalities. Computed tomography is not desirable in childhood because of radiation exposure. Magnetic resonance imaging or magnetic resonance cholangiopancreatography has become the study of choice in pediatrics because it does not involve radiation and it can detect many chronic changes, including pancreas atrophy, ductal dilatations, small filling defects, strictures, irregularities of the main PD, and irregularity of side branches. ${ }^{75}$ Secretin is commonly used to enhance the normally small PDs in children. ${ }^{76}$ Ductal dilatations (61\%) and irregularities (47\%) were the most common imaging findings present in children with $\mathrm{CP}$ at initial imaging ${ }^{13}$ (Figure 2). In contrast to adults with CP, calcifications were not common in childhood CP (12\% vs 38\%$66 \%) \cdot{ }^{13,30}$ EUS is increasingly used for the diagnosis of pediatric ARP and CP, specifically for microlithiasis and pancreatic anomalies (eg, pancreas divisum). However, there are no validated EUS criteria for children. ERCP should be performed only for therapeutic purposes.

Overall, the evidence on which the pediatric AP, ARP and $\mathrm{CP}$ recommendations are based for diagnosis is still weak and requires further research. 


\section{Management}

The core principles of management of AP flares in children - whether due to a single acute episode, ARP, or CP inflammatory flares-are similar to those in adults. ${ }^{77}$ First, one should try to ascertain the risk factors for pancreatitis and remove or target their treatment, such as cholecystectomy for gallstone pancreatitis. Second, attempts should be made to minimize inflammatory damage (particularly multiorgan dysfunction), for example, by providing goaldirected intravenous hydration and early nutrition. ${ }^{78,79}$ If introduced within 24-48 hours, enteral nutrition is beneficial in pediatric AP and can shorten the length of hospitalization compared with complete enteral restriction (ie, nil per os). ${ }^{80}$ Most children with AP can tolerate early enteral nutrition, but there is still a medical culture of introducing feedings late in the course, keeping them fasted longer than needed, or unnecessarily offering them total parenteral nutrition. ${ }^{81}$ Third, patients should be evaluated for complications of pancreatitis, including intra-and peripancreatic collections, including acute fluid collections, necrosis, and pseudocysts, and extrapancreatic problems such as portal venous thrombosis, intestinal ileus, and peptic ulcer disease. The management of localized pancreatic collections is currently similar to adult management. Fourth, sufficient pain control should be provided. The recent opioid epidemic ${ }^{82}$ has caused challenges for patients with pancreatitis, particularly children, who happen to visit unfamiliar emergency departments. We find it helpful to provide patients with a letter explaining the need for such management and provide opiates, as necessary, for acute flares.

We do not recommend screening of asymptomatic children for pathogenic variants with the exception of a few cases, such as cystic fibrosis screening with consultation by a genetic counselor. ${ }^{83}$ The newly discovered pancreatitis gene mutations are not typically passed on through Mendelian inheritance, and children could have several nonpathogenic mutations, which together adds to the disease risk and creates a more complex picture.

Pain is a significant symptom in pediatric ARP and CP, reported in $~ 80 \%$ children in the INSPPIRE cohort, one third of children already using narcotics. ${ }^{13,14}$ There has been an emphasis on nonopioid medications (eg, gabapentin and pregabalin) ${ }^{84}$ because of the significant addiction associated with opioids, but overall experience with these medications is limited. There are many gaps in our understanding of the nutritional and energy needs and potential macro-and micronutrient deficiencies in children with AP, ARP, or CP, recently summarized by the North American Society of Pediatric Gastroenterology, Hepatology, and Nutrition position statement. ${ }^{85}$ ERCP is reserved as a therapeutic modality to relieve obstruction and provide drainage. ERCP with sphincterotomy, stent placement, and/ or stone removal can provide short-term symptom relief in pediatric ARP or CP. ${ }^{86-88}$ Surgery usually involves a drainage procedure and partial or total resections. Surgical drainage procedures typically require the presence of a PD dilated to $>5-6 \mathrm{~mm}$. The Puestow procedure or longitudinal pancreatojejunostomy is the most commonly used technique. There are no data in the pediatric literature about the utility of cholecystectomy in the setting of idiopathic ARP.

TPIAT has become the surgery of choice for pediatric ARP or CP that has been unresponsive to other therapies. The narcotic independence is $50 \%-80 \%$ at 1 year, ${ }^{89-94}$ with $10 \%-20 \%$ of 
patients still taking narcotics at 10-year follow-up. ${ }^{89,92}$ Similarly, insulin independence is w40\% at 10-year follow-up in most children. ${ }^{89}$ Younger children ( $<8$ years) seem to have a more favorable response with higher rates of pain relief and insulin independence. ${ }^{95}$ Longterm outcome data ( $>20-30$ years) that would be most significant for the pediatric group are not yet available. A new multicenter study, Prospective Observational Study of TPIAT, plans to follow TPIAT recipients longitudinally with the aim to identify best timing for TPIAT to optimize pain relief, quality of life, and diabetes outcomes. ${ }^{96}$

There is a paucity of treatment options for pediatric AP, ARP, and CP. Future studies should involve a better understanding of the natural history and role of various risk factors in disease onset and progression.

\section{Prognosis and Natural History}

Most children who present with AP will have mild severity of disease, although a substantial portion will require intensive care unit admission for transient multiorgan dysfunction. ${ }^{97}$ Fortunately, mortality rates are overall lower than 5\%. ${ }^{4}$ Approximately $15 \%-35 \%$ of all children with AP will go on to have recurrences. The exceptions are those in whom risk factors are clearly identified and can be mitigated (eg, gallstones, medications, hypertriglyceridemia, or hypercalcemia). In a single-center study, the progression from AP to ARP occurred in just 5 months and was associated with higher weight percentile, male sex, and pancreatic necrosis at the first AP attack. ${ }^{98}$ Interestingly, in the INSPPIRE cohort, an obese or overweight body habitus delayed the progression from ARP to CP. ${ }^{99}$ What is sobering is that approximately $20 \%-40 \%$ of children with ARP will quickly progress, within 2-5 years of the start of AP, to a diagnosis of CP. ${ }^{13,100}$ Although there are currently few data on the role of smoking or alcohol on pediatric pancreatitis progression, based on the alarming rates reported with these toxins in adults with pancreatitis, ${ }^{101}$ we generally proscribe their use in children with ARP. Longitudinal studies are necessary in patients diagnosed with pancreatitis during childhood to ascertain the natural history of progression from ARP to CP, then EPI and diabetes, and potentially pancreatic cancer and, importantly, to identify the determinants that accelerate and, conversely, retard progression. Currently, there are no recommended guidelines to monitor patients' progression from ARP to $\mathrm{CP}$ and to monitor complications of CP such as EPI and diabetes. The INSPPIRE 2 Cohort Study in the Consortium for the Study of Chronic Pancreatitis, Diabetes, and Pancreatic Cancer aims to follow children with ARP or CP annually and perform fecal elastase, fasting blood glucose and hemoglobin A1c, and oral glucose tolerance testing as needed to determine disease progression. ${ }^{102}$ Such studies will help lay the necessary framework to test interventions and develop optimal algorithms to more effectively and precisely treat the burden of pancreatitis in children. Pancreatic cancer is rare in the pediatric group, but its incidence is known to increase risk significantly in adults with hereditary pancreatitis (estimated cumulative risk of $40 \%$ at 70 years of age). ${ }^{103} \mathrm{~A}$ recent systematic review and meta-analysis study found no association between SPINK1 mutations and pancreatic cancer, whereas cystic fibrosis transmembrane generator gene mutations modestly increased the risk. ${ }^{104}$ 


\section{Pediatric vs Adult Pancreatitis: Contrasts and Similarities}

Pediatric pancreatitis was an unknown entity with increased recognition within the past 2 decades. AP is currently seen in children and is almost as common as it is in adults, with a large variety of etiologies and relatively low complication risk and mortality in children compared with adults. Children with ARP or CP seem to have mostly genetic or anatomic risk factors compared with environmental risk factors predominating in adults. In older children, environmental and autoimmune risk factors start to emerge. Disease burden is equally high in pediatric and adult CP.

\section{Conclusions}

There have been substantial developments in pediatric pancreatology just within the past decade in terms of a better understanding of risk factors, epidemiology, and disease burden. Longitudinal studies are needed to better understand the role of risk factors in disease progression and burden, as are randomized controlled clinical trials to identify the best treatment approaches. Currently, there are only a handful of clinical trials in pediatric pancreatitis, including 2 clinical studies that involve early feeding in pediatric AP; intravenous ibuprofen in post-ERCP pancreatitis; the INSPPIRE 2 observational study in pediatric ARP or CP; and behavioral pain therapy in the INSPPIRE 2 population.

\section{Funding}

This work was supported by the National Institute of Diabetes and Digestive and Kidney Diseases (grants R21 DK096327, U01 DK108334, and R01 DK097820 to Aliye Uc) of the National Institutes of Health. The content is solely the responsibility of the authors and does not necessarily represent the official views of the National Institutes of Health.

\section{Biography}

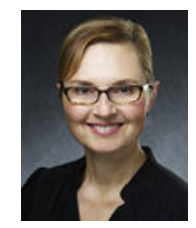

Aliye Uc

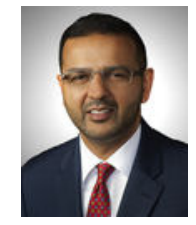

Sohail Z. Husain

\section{Abbreviations used in this paper}

AP

acute pancreatitis 

ARP
acute recurrent pancreatitis
CP
chronic pancreatitis
EPI
exocrine pancreatic insufficiency
ERCP
endoscopic retrograde cholangiopancreatography
EUS
endoscopic ultrasound
INSPPIRE
International Study Group of Pediatric Pancreatitis: In Search for a Cure
PD
pancreatic duct
PRSS1
cationic trypsinogen gene
SPINK1
serine protease inhibitor Kazal type 1 gene
TPIAT
total pancreatectomy and islet autotransplantation

\section{References}

1. Morinville VD, Barmada MM, Lowe ME. Increasing incidence of acute pancreatitis at an American pediatric tertiary care center: is greater awareness among physicians responsible? Pancreas 2010;39:5-8. [PubMed: 19752770]

2. Nydegger A, Heine RG, Ranuh R, et al. Changing incidence of acute pancreatitis: 10-year experience at the Royal Children's Hospital, Melbourne. J Gastroenterol Hepatol 2007;22:13131316. [PubMed: 17489962]

3. Park A, Latif SU, Shah AU, et al. Changing referral trends of acute pancreatitis in children: A 12year single-center analysis. J Pediatr Gastroenterol Nutr 2009;49:316-322. [PubMed: 19503003]

4. Bai HX, Lowe ME, Husain SZ. What have we learned about acute pancreatitis in children? J Pediatr Gastroenterol Nutr 2011;52:262-270. [PubMed: 21336157]

5. Sellers ZM, MacIsaac D, Yu H, et al. Nationwide trends in acute and chronic pancreatitis among privately insured children and non-elderly adults in the United States, 2007-2014. Gastroenterology 2018;155: 469-478.e1. [PubMed: 29660323]

6. Yadav D, Lowenfels AB. Trends in the epidemiology of the first attack of acute pancreatitis: a systematic review. Pancreas 2006;33:323-330. [PubMed: 17079934]

7. Frey CF, Zhou H, Harvey DJ, et al. The incidence and case-fatality rates of acute biliary, alcoholic, and idiopathic pancreatitis in California, 1994-2001. Pancreas 2006;33:336-344. [PubMed: 17079936]

8. Yadav D, O'Connell M, Papachristou GI. Natural history following the first attack of acute pancreatitis. Am J Gastroenterol 2012;107:1096-1103. [PubMed: 22613906]

9. Morinville VD, Husain SZ, Bai H, et al. Definitions of pediatric pancreatitis and survey of present clinical practices. J Pediatr Gastroenterol Nutr 2012;55:261-265. [PubMed: 22357117]

10. Bellin MD, Schwarzenberg SJ, Cook M, et al. Pediatric autologous islet transplantation. Curr Diab Rep 2015; 15:67. [PubMed: 26275441]

11. Spanier B, Bruno MJ, Dijkgraaf MG. Incidence and mortality of acute and chronic pancreatitis in the Netherlands: a nationwide record-linked cohort study for the years 1995-2005. World J Gastroenterol 2013; 19:3018-3026. [PubMed: 23716981]

12. Yadav D, Timmons L, Benson JT, et al. Incidence, prevalence, and survival of chronic pancreatitis: a population-based study. Am J Gastroenterol 2011; 106:2192-2199. [PubMed: 21946280] 
13. Schwarzenberg SJ, Bellin M, Husain SZ, et al. Pediatric chronic pancreatitis is associated with genetic risk factors and substantial disease burden. J Pediatr 2015; 166:890-896 e1. [PubMed: 25556020]

14. Kumar S, Ooi CY, Werlin S, et al. Risk factors associated with pediatric acute recurrent and chronic pancreatitis: lessons from INSPPIRE. JAMA Pediatr 2016;170:562-529. [PubMed: 27064572]

15. Ting J, Wilson L, Schwarzenberg SJ, et al. Direct costs of acute recurrent and chronic pancreatitis in children in the INSPPIRE registry. J Pediatr Gastroenterol Nutr 2016;62:443-449. [PubMed: 26704866]

16. Lopez MJ. The changing incidence of acute pancreatitis in children: a single-institution perspective. J Pediatrics 2002;140:622-624.

17. Hornung LN, Szabo FK, Kalkwarf HJ, et al. Stabilized incidence of pediatric acute pancreatitis. Pancreas 2018; 47:e60-e62. [PubMed: 30199490]

18. Bradley EL III. A clinically based classification system for acute pancreatitis. Summary of the International Symposium on Acute Pancreatitis, Atlanta, Ga, September 11 through 13, 1992. Arch Surg 1993; 128:586-590. [PubMed: 8489394]

19. Morinville VD, Husain SZ, Bai H, et al. Definitions of pediatric pancreatitis and survey of current clinical practices. J Pediatr Gastroenterol Nutr 2013;56:459.

20. Ma MH, Bai HX, Park AJ, et al. Risk factors associated with biliary pancreatitis in children. J Pediatr Gastroenterol Nutr 2012;54:651-656. [PubMed: 22002481]

21. Taylor CJ, Chen K, Horvath K, et al. ESPGHAN and NASPGHAN report on the assessment of exocrine pancreatic function and pancreatitis in children. J Pediatr Gastroenterol Nutr 2015;61:144-153. [PubMed: 25915425]

22. Joergensen M, Brusgaard K, Crüger DG, et al. Incidence, prevalence, etiology, and prognosis of first-time chronic pancreatitis in young patients: a nationwide cohort study. Dig Dis Sci 2010;55:2988-2998. [PubMed: 20108119]

23. Saito N, Suzuki M, Sakurai Y, et al. Genetic analysis of Japanese children with acute recurrent and chronic pancreatitis. J Pediatr Gastroenterol Nutr 2016;63: 431-436. [PubMed: 27409067]

24. Schwarzenberg SJ, Bellin M, Husain SZ, et al. Pediatric chronic pancreatitis is associated with genetic risk factors and substantial disease burden. J Pediatr 2015; 166:890-896.e1. [PubMed: 25556020]

25. Wang W, Liao Z, Li Z-S, et al. Chronic pancreatitis in Chinese children: etiology, clinical presentation and imaging diagnosis. J Gastroenterol Hepatol 2009; 24:1862-1868. [PubMed: 19793170]

26. Wejnarska K, Kolodziejczyk E, Wertheim-Tysarowska K, et al. The etiology and clinical course of chronic pancreatitis in children with early onset of the disease. J Pediatr Gastroenterol Nutr 2016;63:665-670. [PubMed: 27673710]

27. Conwell DL, Banks PA, Sandhu BS, et al. Validation of demographics, etiology, and risk factors for chronic pancreatitis in the USA: a report of the North American Pancreas Study (NAPS) Group. Dig Dis Sci 2017; 62:2133-2140. [PubMed: 28600657]

28. Romagnuolo J, Talluri J, Kennard E, et al. Clinical profile, etiology, and treatment of chronic pancreatitis in North American women: analysis of a large multicenter cohort. Pancreas 2016;45:934-940. [PubMed: 26967451]

29. Cote GA, Yadav D, Slivka A, et al. Alcohol and smoking as risk factors in an epidemiology study of patients with chronic pancreatitis. Clin Gastroenterol Hepatol 2011; 9:266-273; quiz e27. [PubMed: 21029787]

30. Grabarczyk AM, Oracz G, Wertheim-Tysarowska K, et al. Chymotrypsinogen C genetic variants, including c. 180TT, are strongly associated with chronic pancreatitis in pediatric patients. J Pediatr Gastroenterol Nutr 2017; 65:652-657. [PubMed: 28968289]

31. Witt H, Beer S, Rosendahl J, et al. Variants in CPA1 are strongly associated with early onset chronic pancreatitis. Nat Genet 2013;45:1216-1220. [PubMed: 23955596]

32. Fjeld K, Weiss FU, Lasher D, et al. A recombined allele of the lipase gene CEL and its pseudogene CELP confers susceptibility to chronic pancreatitis. Nat Genet 2015; 47:518-522. [PubMed: 25774637] 
33. Ragvin A, Fjeld K, Weiss FU, et al. The number of tandem repeats in the carboxyl-ester lipase (CEL) gene as a risk factor in alcoholic and idiopathic chronic pancreatitis. Pancreatology 2013;13:29-32. [PubMed: 23395566]

34. Chang YJ, Chao HC, Kong MS, et al. Acute pancreatitis in children. Acta Paediatr 2011;100:740744. [PubMed: 21251058]

35. Lautz TB, Chin AC, Radhakrishnan J. Acute pancreatitis in children: spectrum of disease and predictors of severity. J Pediatr Surg 2011;46:1144-1149. [PubMed: 21683213]

36. Fogel EL, Toth TG, Lehman GA, et al. Does endoscopic therapy favorably affect the outcome of patients who have recurrent acute pancreatitis and pancreas divisum? Pancreas 2007;34:21-45. [PubMed: 17198181]

37. Lin TK, Abu-El-Haija M, Nathan JD, et al. Pancreas divisum in pediatric acute recurrent and chronic pancreatitis: report from INSPPIRE. J Clin Gastroenterol 10.1097/MCG. 0000000000001063. E-pub ahead of print.

38. Bertin C, Pelletier AL, Vullierme MP, et al. Pancreas divisum is not a cause of pancreatitis by itself but acts as a partner of genetic mutations. Am J Gastroenterol 2012; 107:311-317. [PubMed: 22158025]

39. Garg PK, Khajuria R, Kabra M, et al. Association of SPINK1 gene mutation and CFTR gene polymorphisms in patients with pancreas divisum presenting with idiopathic pancreatitis. J Clin Gastroenterol 2009; 43:848-852. [PubMed: 19593166]

40. Cote GA. Sphincterotomy for acute recurrent pancreatitis Available at: https://clinicaltrials.gov/ct2/ show/NCT03609944. Last update 102018.

41. Husain SZ, Srinath AI. What's unique about acute pancreatitis in children: risk factors, diagnosis and management. Nat Rev Gastroenterol Hepatol 2017; 14:366-372. [PubMed: 28293024]

42. Chen JJ, Lee HC, Yeung CY, et al. Meta-analysis: the clinical features of the duodenal duplication cyst. J Pediatr Surg 2010;45:1598-1606. [PubMed: 20713206]

43. Wen L, Javed TA, Yimlamai D, et al. Transient high pressure in pancreatic ducts promotes inflammation and alters tight junctions via calcineurin signaling in mice. Gastroenterology 2018;155:1250-1263.e5. [PubMed: 29928898]

44. Acosta JM, Ledesma CL. Gallstone migration as a cause of acute pancreatitis. N Engl J Med 1974; 290:484-487. [PubMed: 4810815]

45. Garg PK, Tandon RK, Madan K. Is biliary microlithiasis a significant cause of idiopathic recurrent acute pancreatitis? A long-term follow-up study. Clin Gastroenterol Hepatol 2007;5:75-79. [PubMed: 16931169]

46. Ros E, Navarro S, Bru C, et al. Occult microlithiasis in 'idiopathic' acute pancreatitis: prevention of relapses by cholecystectomy or ursodeoxycholic acid therapy. Gastroenterology 1991;101:1701-1709. [PubMed: 1955135]

47. Kanth R, Samji NS, Inaganti A, et al. Endotherapy in symptomatic pancreas divisum: a systematic review. Pancreatology 2014;14:244-250. [PubMed: 25062871]

48. Bai HX, Ma MH, Orabi AI, et al. Novel characterization of drug-associated pancreatitis in children. J Pediatr Gastroenterol Nutr 2011;53:423-428. [PubMed: 21681111]

49. Karch FE, Lasagna L. Adverse drug reactions. A critical review. JAMA 1975;234:1236-1241. [PubMed: 1242749]

50. Husain SZ, Morinville V, Pohl J, et al. Toxic-metabolic risk factors in pediatric pancreatitis: recommendations for diagnosis, management, and future research. J Pediatr Gastroenterol Nutr 2016;62:609-617. [PubMed: 26594832]

51. Wilson A, Jansen LE, Rose RV, et al. HLA-DQA1-HLA-DRB1 polymorphism is a major predictor of azathioprine-induced pancreatitis in patients with inflammatory bowel disease. Aliment Pharmacol Ther 2018;47:615-620. [PubMed: 29270995]

52. Heap GA, Weedon MN, Bewshea CM, et al. HLA-DQA1-HLA-DRB1 variants confer susceptibility to pancreatitis induced by thiopurine immunosuppressants. Nat Genet 2014;46:1131-1134. [PubMed: 25217962]

53. Eisses JF, Criscimanna A, Dionise ZR, et al. Valproic acid limits pancreatic recovery after pancreatitis by inhibiting histone deacetylases and preventing acinar redifferentiation programs. Am J Pathol 2015;185:3304-3315. [PubMed: 26476347] 
54. Milman HA, Cooney DA, Young DM. Role of pancreatic L-asparagine synthetase in homeostasis of L-asparagine. Am J Physiol Endocrinol Metab 1979;236:E746-E753.

55. Logsdon CD, Ji B. The role of protein synthesis and digestive enzymes in acinar cell injury. Nat Rev Gastroenterol Hepatol 2013;10:362-370. [PubMed: 23507798]

56. Chalasani N, Bonkovsky HL, Fontana R, et al. Features and outcomes of 899 patients with druginduced liver injury: the DILIN prospective study. Gastroenterology 2015;148:1340-1352 e7. [PubMed: 25754159]

57. Sutherland I, Ledder O, Crameri J, et al. Pancreatic trauma in children. Pediatr Surg Int 2010;26:1201-1206. [PubMed: 20803148]

58. Bultron G, Seashore MR, Pashankar DS, et al. Recurrent acute pancreatitis associated with propionic acidemia. J Pediatr Gastroenterol Nutr 2008;47:370-371. [PubMed: 18728537]

59. Bhoomagoud M, Jung T, Atladottir J, et al. Reducing extracellular pH sensitizes the acinar cell to secretagogue-induced pancreatitis responses in rats. Gastroenterology 2009;137:1083-1092. [PubMed: 19454288]

60. Rawla P, Bandaru SS, Vellipuram AR. Review of infectious etiology of acute pancreatitis. Gastroenterol Res 2017;10:153-158.

61. Parenti DM, Steinberg W, Kang P. Infectious causes of acute pancreatitis. Pancreas 1996;13:356371. [PubMed: 8899796]

62. Kandula L, Lowe ME. Etiology and outcome of acute pancreatitis in infants and toddlers. J Pediatr 2008; 152:106-110 e1. [PubMed: 18154910]

63. Helbling R, Lava SA, Simonetti GD, et al. Gallbladder and pancreas in Henoch-Schonlein purpura: review of the literature. J Pediatr Gastroenterol Nutr 2016; 62:457-461. [PubMed: 26308313]

64. Zhang Q, Guo Q, Gui M, et al. Henoch-Schonlein purpura with acute pancreatitis: analysis of 13 cases. BMC Pediatr 2018;18:159. [PubMed: 29751784]

65. Asano T, Sasaki N, Yashiro K, et al. Acute pancreatitis with Kawasaki disease: analysis of cases with elevated serum amylase levels. Eur J Pediatr 2005;164:180-181. [PubMed: 15717180]

66. Srinath AI, Gupta N, Husain SZ. Probing the association of pancreatitis in inflammatory bowel disease. Inflamm Bowel Dis 2016;22:465-475. [PubMed: 26535870]

67. Scheers I, Palermo JJ, Freedman S, et al. Autoimmune pancreatitis in children: characteristic features, diagnosis, and management. Am J Gastroenterol 2017; 112:1604-1611. [PubMed: 28374818]

68. Scheers I, Palermo JJ, Freedman S, et al. Recommendations for diagnosis and management of autoimmune pancreatitis in childhood: consensus from INSPPIRE. J Pediatr Gastroenterol Nutr 2018;67:232-236. [PubMed: 29746340]

69. Parniczky A, Abu-El-Haija M, Husain S, et al. EPC/ HPSG evidence-based guidelines for the management of pediatric pancreatitis. Pancreatology 2018;18: 146-160. [PubMed: 29398347]

70. Park AJ, Latif SU, Ahmad MU, et al. A comparison of presentation and management trends in acute pancreatitis between infants/toddlers and older children. J Pediatr Gastroenterol Nutr 2010;51:167-170. [PubMed: 20479687]

71. Abu-El-Haija M, Kumar S, Szabo F, et al. Classification of acute pancreatitis in the pediatric population: clinical report from the NASPGHAN Pancreas Committee. J Pediatr Gastroenterol Nutr 2017;64:984-990. [PubMed: 28333771]

72. Li W, Luo S, Zhu Y, et al. Concordance of the Balthazar Grade and the Revised Atlanta Classification: proposing a modified Balthazar Grade to predict the severity of acute pancreatitis in pediatric population. Pancreas 2018;47:1312-1316. [PubMed: 30286016]

73. Coffey MJ, Nightingale S, Ooi CY. Serum lipase as an early predictor of severity in pediatric acute pancreatitis. J Pediatr Gastroenterol Nutr 2013; 56:602-608. [PubMed: 23403441]

74. Gariepy CE, Heyman MB, Lowe ME, et al. Causal evaluation of acute recurrent and chronic pancreatitis in children: consensus from the INSPPIRE group. J Pediatr Gastroenterol Nutr 2017;64:95-103. [PubMed: 27782962]

75. Hansen TM, Nilsson M, Gram M, et al. Morphological and functional evaluation of chronic pancreatitis with magnetic resonance imaging. World J Gastroenterol 2013;19:7241-7246. [PubMed: 24259954] 
76. Manfredi R, Lucidi V, Gui B, et al. Idiopathic chronic pancreatitis in children: MR cholangiopancreatography after secretin administration. Radiology 2002;224:675-682. [PubMed: 12202699]

77. Abu-El-Haija M, Kumar S, Quiros JA, et al. Management of acute pancreatitis in the pediatric population: a clinical report from the North American Society for Pediatric Gastroenterology, Hepatology and Nutrition Pancreas Committee. J Pediatr Gastroenterol Nutr 2018;66:159-176. [PubMed: 29280782]

78. Szabo FK, Fei L, Cruz LA, et al. Early enteral nutrition and aggressive fluid resuscitation are associated with improved clinical outcomes in acute pancreatitis. J Pediatr 2015;167:397-402.e1. [PubMed: 26210842]

79. Buxbaum JL, Quezada M, Da B, et al. Early aggressive hydration hastens clinical improvement in mild acute pancreatitis. Am J Gastroenterol 2017;112:797-803. [PubMed: 28266591]

80. Mosztbacher D, Farkas N, Solymar M, et al. Restoration of energy level in the early phase of acute pediatric pancreatitis. World J Gastroenterol 2017;23:957-963. [PubMed: 28246469]

81. Cole S, Wakeham M, Werlin S, et al. Classification and nutrition management of acute pancreatitis in the pediatric intensive care unit. J Pediatr Gastroenterol Nutr 2018;67:755-759. [PubMed: 30211843]

82. Vadivelu N, Kai AM, Kodumudi V, et al. The opioid crisis: a comprehensive overview. Curr Pain Headache Rep 2018;22:16. [PubMed: 29476358]

83. Zator Z, Whitcomb DC. Insights into the genetic risk factors for the development of pancreatic disease. Therap Adv Gastroenterol 2017;10:323-336.

84. Olesen SS, Bouwense SA, Wilder-Smith OH, et al. Pregabalin reduces pain in patients with chronic pancreatitis in a randomized, controlled trial. Gastroenterology 2011; 141:536-543. [PubMed: 21683078]

85. Abu-El-Haija M, Uc A, Werlin SL, et al. Nutritional considerations in pediatric pancreatitis: a position paper from the NASPHAN Pancreas Committee and ESPHAN Cystic Fibrosis/Pancreas Working Group. J Pediatr Gastroenterol Nutr 2018;67:131-143. [PubMed: 29927872]

86. Troendle DM, Barth BA. Pediatric considerations in endoscopic retrograde cholangiopancreatography. Gastrointest Endosc Clin N Am 2016;26:119-136. [PubMed: 26616900]

87. Agarwal J, Nageshwar Reddy D, Talukdar R, et al. ERCP in the management of pancreatic diseases in children. Gastrointest Endosc 2014;79:271-278. [PubMed: 24060520]

88. Oracz G, Pertkiewicz J, Kierkus J, et al. Efficiency of pancreatic duct stenting therapy in children with chronic pancreatitis. Gastrointest Endosc 2014;80:1022-1029. [PubMed: 24852105]

89. Chinnakotla S, Bellin MD, Schwarzenberg SJ, et al. Total pancreatectomy and islet autotransplantation in children for chronic pancreatitis: indication, surgical techniques, postoperative management, and long-term outcomes. Ann Surg 2014;260:56-64. [PubMed: 24509206]

90. Bellin MD, Carlson AM, Kobayashi T, et al. Outcome after pancreatectomy and islet autotransplantation in a pediatric population. J Pediatr Gastroenterol Nutr 2008; 47:37-44. [PubMed: 18607267]

91. Wilson GC, Sutton JM, Salehi M, et al. Surgical out-comes after total pancreatectomy and islet cell auto-transplantation in pediatric patients. Surgery 2013; 154:777-783; discussion 783-784. [PubMed: 24074415]

92. Chinnakotla S, Radosevich DM, Dunn TB, et al. Long-term outcomes of total pancreatectomy and islet auto transplantation for hereditary/genetic pancreatitis. J Am Coll Surg 2014;218:530-543. [PubMed: 24655839]

93. Bellin MD, Freeman ML, Schwarzenberg SJ, et al. Quality of life improves for pediatric patients after total pancreatectomy and islet auto transplant for chronic pancreatitis. Clin Gastroenterol Hepatol 2011;9:793-799. [PubMed: 21683160]

94. Sutherland DE, Radosevich DM, Bellin MD, et al. Total pancreatectomy and islet autotransplantation for chronic pancreatitis. J Am Coll Surg 2012;214:409-424; discussion 424 426. [PubMed: 22397977] 
95. Bellin MD, Forlenza GP, Majumder K, et al. Total pancreatectomy with islet autotransplantation resolves pain in young children with severe chronic pancreatitis. J Pediatr Gastroenterol Nutr 2017;64:440-445. [PubMed: 28231072]

96. Bellin MD, Abu-El-Haija M, Morgan K, et al. A multicenter study of total pancreatectomy with islet autotransplantation (TPIAT): POST (Prospective Observational Study of TPIAT).

Pancreatology 2018; 18:286-290. [PubMed: 29456124]

97. Hornung L, Szabo FK, Kalkwarf HJ, et al. Increased burden of pediatric acute pancreatitis on the health care system. Pancreas 2017;46:1111-1114. [PubMed: 28902779]

98. Sweeny KF, Lin TK, Nathan JD, et al. Rapid progression of acute pancreatitis to acute recurrent pancreatitis in children. J Pediatr Gastroenterol Nutr 2019; 68:104-109. [PubMed: 30234758]

99. Uc A, Zimmerman MB, Wilschanski M, et al. Impact of obesity on pediatric acute recurrent and chronic pancreatitis. Pancreas 2018;47:967-973. [PubMed: 30059474]

100. Hao F, Guo H, Luo Q, et al. Disease progression of acute pancreatitis in pediatric patients. J Surg Res 2016; 202:422-427. [PubMed: 27229118]

101. Singhvi A, Yadav D. Myths and realities about alcohol and smoking in chronic pancreatitis. Curr Opin Gastroenterol 2018;34:355-361. [PubMed: 29965868]

102. Uc A, Perito ER, Pohl JF, et al. INternational Study Group of Pediatric Pancreatitis: In Search for a CuRE Cohort Study: design and rationale for INSPPIRE 2 from the Consortium for the Study of Chronic Pancreatitis, Diabetes, and Pancreatic Cancer. Pancreas 2018; 47:1222-1228. [PubMed: 30325861]

103. Lowenfels AB, Maisonneuve P, DiMagno EP, et al. Hereditary pancreatitis and the risk of pancreatic cancer. International Hereditary Pancreatitis Study Group. J Natl Cancer Inst 1997;89:442-446. [PubMed: 9091646]

104. Cazacu IM, Farkas N, Garami A, et al. Pancreatitis-associated genes and pancreatic cancer risk: a systematic review and meta-analysis. Pancreas 2018; 47:1078-1086. [PubMed: 30134356] 

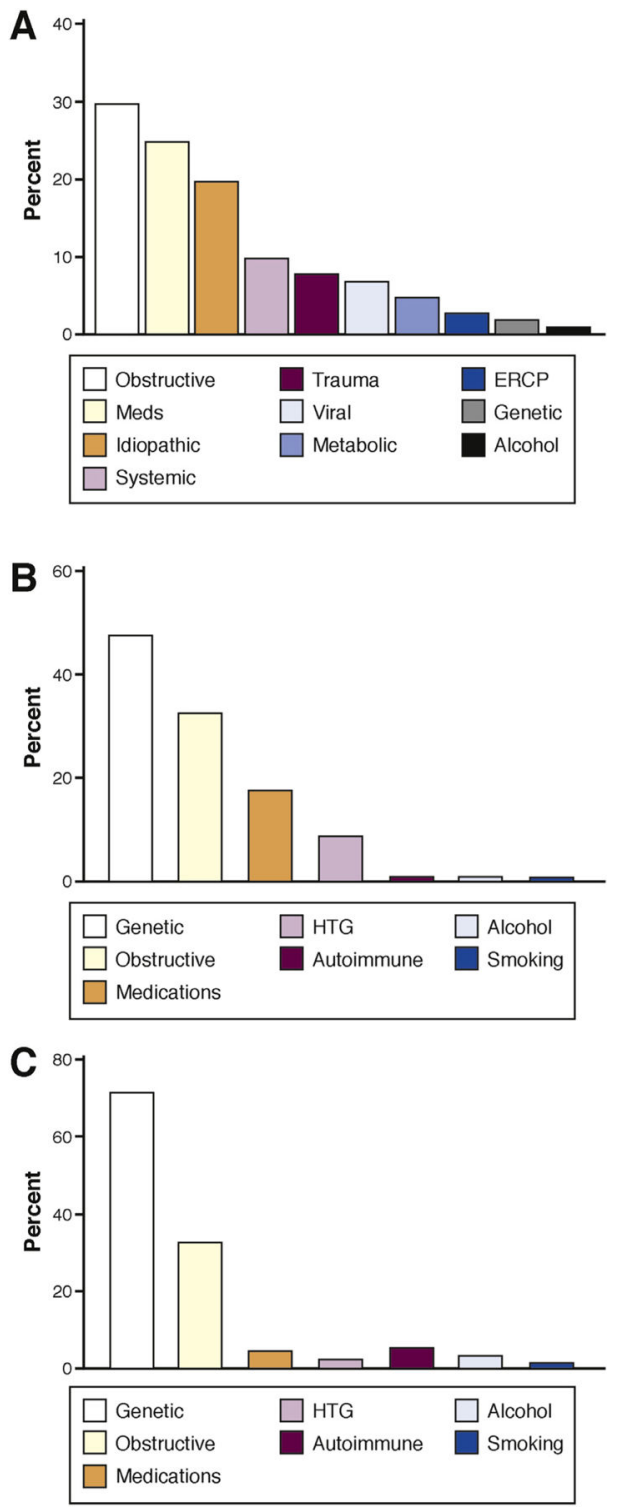

Figure 1.

Risk factors for AP, ARP, and $\mathrm{CP}$ in childhood. ${ }^{14,21}$ Figure shows the most common risk factors for $\mathrm{AP}(A), \mathrm{ARP}(B)$, and $\mathrm{CP}(C)$ in children. HTG, hypertriglyceridemia; Meds, medications. 


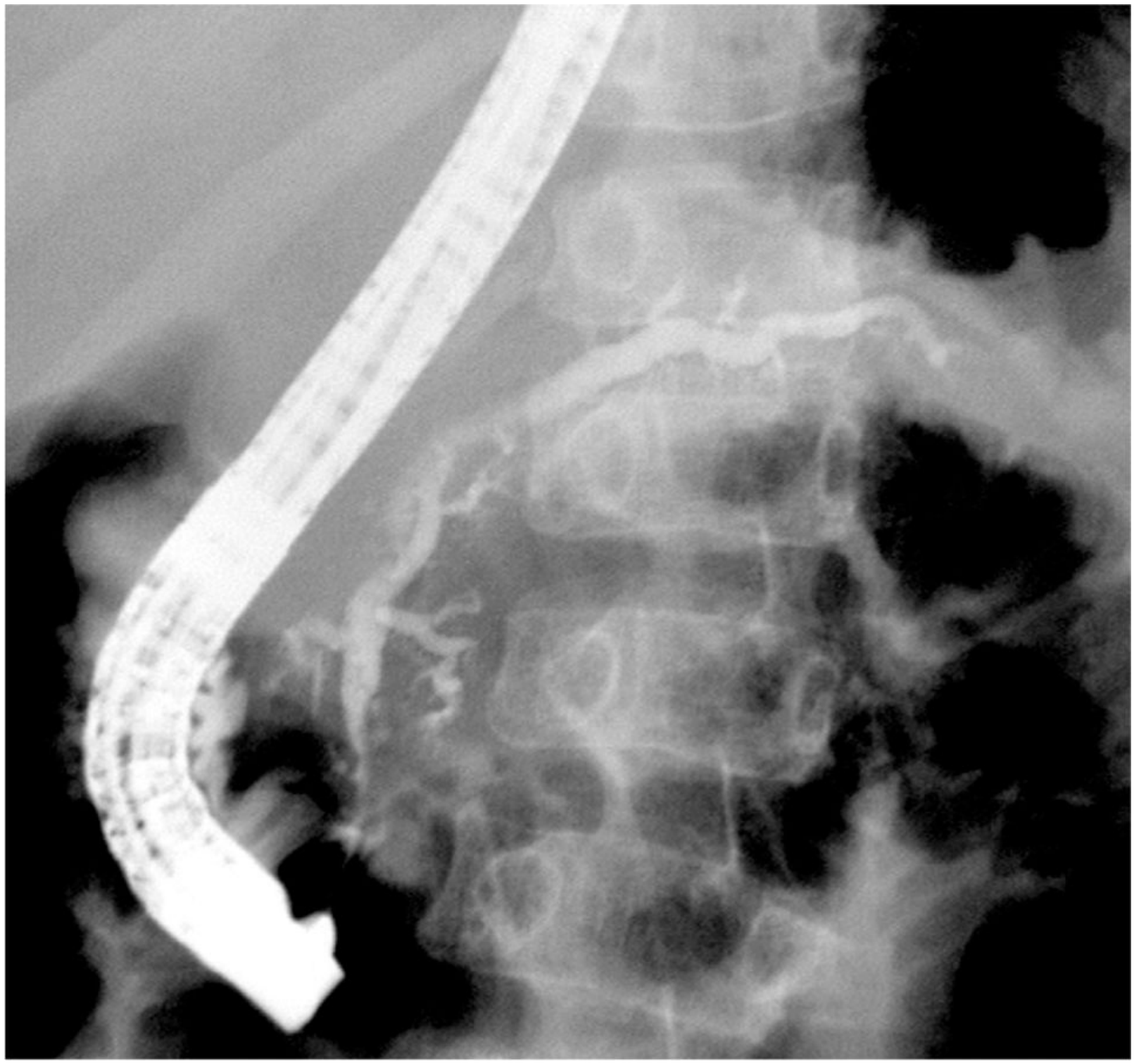

Figure 2.

Imaging changes in pediatric CP. ERCP fluoroscopy image from a 10-year-old boy with hereditary pancreatitis (PRSS1 R122H mutation) shows irregular filling, stricture, and dilatation (up to $4.2 \mathrm{~mm}$ ) of the main PD and its side branches. Image courtesy of Dr Simon Kao, Stead Family Children's Hospital, University of Iowa, Iowa City, Iowa. 
Table 1.

Definitions of Pancreatitis in Children (INSPPIRE Criteria) ${ }^{9}$

\begin{tabular}{|c|c|}
\hline & Clinical Definition \\
\hline $\mathrm{AP}$ & $\begin{array}{l}\text { Requires } \geq 2 \text { of } 3 \text { criteria: } \\
\text { 1. Abdominal pain suggestive of or compatible with AP } \\
\text { 2. Serum amylase and/or lipase activity } \geq 3 \text { times greater than upper limit of normal } \\
\text { 3. Imaging findings characteristic of or compatible with AP }\end{array}$ \\
\hline ARP & $\begin{array}{l}\text { Requires } \geq 2 \text { episodes of AP plus } \\
\text { Complete resolution of pain ( } \geq 1 \text {-mo pain-free interval between diagnoses of AP) } \\
\text { OR } \\
\text { Complete normalization of amylase and lipase between episodes }\end{array}$ \\
\hline $\mathrm{CP}$ & $\begin{array}{l}\text { Requires } \geq 1 \text { of the following } 3 \text { criteria: } \\
\text { 1. Abdominal pain consistent with pancreatic origin and imaging findings suggestive of CP damage }{ }^{a} \\
\text { 2. Evidence of EPI and suggestive pancreatic imaging findings }{ }^{a} \\
\text { 3. Evidence of endocrine pancreatic insufficiency and suggestive pancreatic imaging findings }{ }^{a}\end{array}$ \\
\hline
\end{tabular}

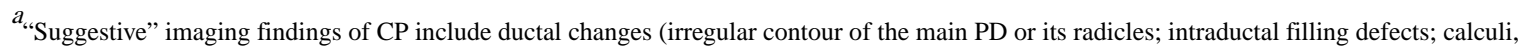
stricture, or dilation) and parenchymal changes (generalized or focal enlargement, irregular contour [accentuated lobular architecture], cavities, calcifications, heterogeneous echotexture). 
Table 2.

Pediatric Acute Recurrent and Chronic Pancreatitis—Diagnostic Approach ${ }^{74}$

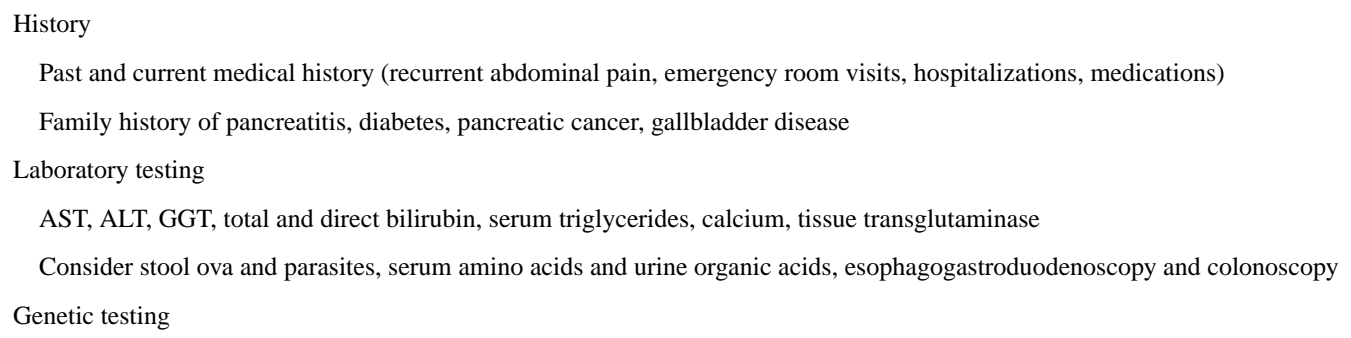

ALT, alanine aminotransferase; AST, aspartate aminotransferase; $C E L$, carboxyl ester lipase gene; $C E L-H Y B$, carboxyl ester lipase hybrid gene; $C F T R$, cystic fibrosis transmembrane generator gene; CPA1, carboxypeptidase 1 gene; $C T R C$, chymotrypsin C gene; GGT, $\gamma$-glutamyl transferase; CT, computed tomography; MRI, magnetic resonance imaging; MRCP, magnetic resonance cholangiopancreatography; TUS, transabdominal ultrasound. 